\title{
Silk Production: The Global Scenario
}

\author{
K. Thiripura Sundari ${ }^{1}$ and P. Ramalakshmi ${ }^{2}$ \\ ${ }^{1}$ Principal, ${ }^{2}$ Assistant Professor of Commerce, \\ Sri Parasakthi College for Women, Courtallam, Tirunelveli, Tamil Nadu, India \\ E-Mail: lakshmiroyalcommerce@gmail.com, kthiripurasundari@gmail.com
}

\begin{abstract}
Silk is a high value-added product and it always ranks comparably higher than any other textile fiber known in human history or in use in present times because of its appreciation in terms of consumer preference, unit values, fashion significance, employment generation, income generating opportunities in producer communities and the intangible value related to the preservation of mankind's cultural heritage. Over the centuries, silk has been recognized for its unique characteristics of comfort, luster and glamour. The most loved fiber, the world over, silk spells luxury, elegance and class with its unparalleled grandeur, the silk fabric has reigned as the undisputed "queen of textiles" over the centuries. The major silk producing countries in the world are; China, India, Uzbekistan, Brazil, Japan, Republic of Korea, Thailand, Vietnam, DPR Korea, Iran, etc. Hence, against this backdrop an attempt is made in this paper to analyze the Global silk production.

Keywords: Silk Fabric, Countries, Luxury, Queen of textiles
\end{abstract}

\section{INTRODUCTION}

Silk is a high value-added product and it always ranks comparably higher than any other textile fiber known in human history or in use in present times because of its appreciation in terms of consumer preference, unit values, fashion significance, employment generation, income generating opportunities in producer communities and the intangible value related to the preservation of mankind's cultural heritage. Over the centuries, silk has been recognized for its unique characteristics of comfort, luster and glamour. The most loved fiber, the world over, silk spells luxury, elegance and class with its unparalleled grandeur, the silk fabric has reigned as the undisputed "queen of textiles" over the centuries. The major silk producing countries in the world are; China, India, Uzbekistan, Brazil, Japan, Republic of Korea, Thailand, Vietnam, DPR Korea, Iran, etc.Few other countries are also engaged in the production of cocoons and raw silk in negligible quantities; Kenya, Botswana, Nigeria, Zambia, Zimbabwe, Bangladesh, Colombia, Egypt, Japan, Nepal, Bulgaria, Turkey, Uganda, Malaysia, Romania, Bolivia, etc. Hence, against this backdrop an attempt is made in this paper to analyze the Global silk production.

\section{OBJECTIVES OF THE STUDY}

1. To analyze the raw silk production of various countries across the globe.
2. To evaluate the production pattern of various countries by adopting suitable statistical tools.

\section{SIGNIFICANCE OF THE STUDY}

While the major producers are in Asia (90\% of mulberry production and almost $100 \%$ of non-mulberry silk), sericulture industries have been lately established in Brazil, Bulgaria, Egypt and Madagascar as well. Sericulture is labour-intensive. About 1 million workers are employed in the silk sector in China. Silk Industry provides employment to 7.9 million people in India, and 20,000 weaving families in Thailand. China is the world's single biggest producer and chief supplier of silk to the world markets.

India is the world's second largest producer. Sericulture can help keeping the rural population employed and to prevent migration to big cities and securing remunerative employment; it requires small investments while providing raw material for textile industries. Against this background, the present paper focuses on the level of global silk production.

\section{METHODOLOGY}

The study is based on secondary data. The secondary data were collected from central silk board annual reports, reports of international sericulture commission, magazines, books and websites. The data have been analyzed with the help of different statistical tools. The data were collected for a period of 10 years from 2006-07 to 2015-16.

\section{ANALYSIS}

The researcher has analyzed Silk production of various countries across the globe. They are China, India, Brazil, Uzbekistan, Japan, Republic of Korea, Thailand, Vietnam, DPR Korea, Iran, were taken for analysis. Suitable statistical tools have been applied to analyse the production trend and meaningful inferences were drawn.

The following Table I shows the raw silk production in various countries for a period of 10 years from 2006-07 to 2015-16. 
TABLE I RAW SILK PRODUCTION IN VARIOUS COUNTRIES (MT)

\begin{tabular}{|c|c|c|c|c|c|c|c|c|c|c|}
\hline Year & China & India & Brazil & Uzbekistan & Thailand & Vietnam & $\begin{array}{c}\text { Korea } \\
\text { republic }\end{array}$ & Japan & Bangladesh & Bulgaria \\
\hline $2006-07$ & 130000 & 18475 & 1387 & 950 & 1080 & 750 & 150 & 150 & 38 & 6.5 \\
\hline $2007-08$ & 108420 & 18320 & 1220 & 950 & 760 & 750 & 150 & 150 & 39 & 7.5 \\
\hline $2008-09$ & 98620 & 18370 & 1177 & 865 & 1100 & 680 & 135 & 95 & 39.50 & 7.5 \\
\hline $2009-10$ & 104000 & 19690 & 811 & 750 & 665 & 550 & 135 & 90 & 40 & 6.3 \\
\hline $2010-11$ & 115000 & 20410 & 770 & 940 & 655 & 550 & 300 & 54 & 40 & 9.4 \\
\hline $2011-12$ & 104000 & 23060 & 558 & 940 & 655 & 500 & 300 & 42 & 38 & 6 \\
\hline $2012-13$ & 126000 & 23679 & 614 & 940 & 655 & 450 & 300 & 30 & 42.50 & 8.5 \\
\hline $2013-14$ & 130000 & 26480 & 550 & 980 & 680 & 475 & 300 & 30 & 43 & 8.5 \\
\hline $2014-15$ & 146000 & 28708 & 560 & 1100 & 692 & 420 & 320 & 30 & 44.5 & 8 \\
\hline $2015-16$ & 170000 & 28523 & 600 & 1200 & 698 & 450 & 350 & 30 & 44 \\
\hline
\end{tabular}

\section{A. Raw Silk Production in Various Countries(Consolidated)}

The following table shows the consolidated analysis of raw silk production in various countries, by adopting various statistical tools.

TABLE II RAW SILK PRODUCTION IN VARIOUS COUNTRIES (CONSOLIDATED)

\begin{tabular}{|l|c|c|c|c|c|c|}
\hline \multirow{2}{*}{ Countries } & \multicolumn{7}{|c|}{ Statistical Measures } \\
\cline { 2 - 7 } & CGR & Mean & Standard Deviation & Skewness & Kurtosis & Co-Variance \\
\hline China & $3.92 \%$ & 123204.0 & 22204.97 & 1.042 & 0.831 & $18.02 \%$ \\
\hline India & $5.94 \%$ & 22571.50 & 4154.0186 & 1.063 & 0.848 & $18.40 \%$ \\
\hline Brazil & $-10.3 \%$ & 824.70 & 318.20 & 0.880 & -0.933 & $38.58 \%$ \\
\hline Uzbekistan & $2.7 \%$ & 961.50 & 121.15 & 0.456 & 1.427 & $12.60 \%$ \\
\hline Thailand & $-4.13 \%$ & 764.00 & 174.74 & 1.650 & 1.123 & $22.87 \%$ \\
\hline Vietnam & $-9.10 \%$ & 557.50 & 125.32 & 0.724 & -1.107 & $22.48 \%$ \\
\hline $\begin{array}{l}\text { Korea } \\
\text { Republic }\end{array}$ & $12.4 \%$ & 244.00 & 88.8 & -0.380 & -2.103 & $36.39 \%$ \\
\hline Japan & $-9.13 \%$ & 70.10 & 48.60 & 0.918 & -0.700 & $69.33 \%$ \\
\hline Bangladesh & $3.08 \%$ & 40.85 & 2.44 & 0.364 & 1.545 & $5.97 \%$ \\
\hline Bulgaria & $6.36 \%$ & 7.62 & 1.09 & 1.005 & 1.232 & $14.30 \%$ \\
\hline
\end{tabular}

Table II shows that Korea Republic has a high positive compound growth rate of raw silk production of $12.4 \%$ and Japan has a high negative compound growth rate of raw silk production of $-19.13 \%$. Table further shows that the production of raw silk is high in China, the mean production of China is 123204.0 crores and the production of raw silk is low in Bulgaria, the mean production of Bulgaria is 7.62 crores. It is clear from table that the co-variance of raw silk production is high in Japan, it has $69.33 \%$ and the covariance of raw silk production is low in Bangladesh, it has $5.97 \%$.

\section{FINDINGS}

1. It was found that the Raw silk production in China has increased from $130000 \mathrm{MT}$ in 2006-07 to $170000 \mathrm{MT}$ in 2015-16. It is inferred that the production of Raw silk has a Compound Growth Rate of 3.92 per cent.
2. It was found that Raw silk production in India has increased from $18475 \mathrm{MT}$ in 2006-07 to 28523MT in 2015-16. It is inferred that the production of Raw silk has a Compound Growth Rate of 5.94 per cent.

3. It was found that the Raw silk production in Brazil has decreased from 1387MT in 2006-07 to 600 MT in 2015-16. It is inferred that the production of Raw silk has a Compound Growth Rate of-10.3 per cent.

4. It was found that the Raw silk production in Uzbekistan has increased from $950 \mathrm{MT}$ in 2006-07 to $1200 \mathrm{MT}$ in 2015-16. It is inferred that the production of Raw silk has a Compound Growth Rate of 2.7per cent.

5. It was found that the Raw silk production in Thailand has decreased from1080 MT in 2006-07 to698 MT in 2015-16. It is inferred that the production of Raw silk has a Compound Growth Rate of-4.13 per cent.

6. It was found that the Raw silk production in Vietnam has decreased from $750 \mathrm{MT}$ in 2006-07 to $450 \mathrm{MT}$ in 
2015-16. It is inferred that the production of Raw silk has a Compound Growth Rate of -9.10per cent.

7. It was found that the Raw silk production in Korea Republic has increased from 150 MT in 2006-07 to 350 MT in 2015-16. It is inferred that the production of Raw silk has a Compound Growth Rate of 12.4per cent.

8. It was found that the Raw silk production in Japan has decreased from 150 MT in 2006-07 to 30 MT in 201516. It is inferred that the production of Raw silk has a Compound Growth Rate of-19.13 per cent.

9. It was found that the Raw silk production in Bangladesh has increased from 38 MT in 2006-07 to 44 MT in 2015-16. It is inferred that the production of Raw silk has a Compound Growth Rate of 3.08 per cent.

10. It was found that the Raw silk production in Bulgaria has decreased from 6.5 MT in 2006-07 to $8 \mathrm{MT}$ in 2015-16. It is inferred that the production of Raw silk has a Compound Growth Rate of 6.36 per cent.

\section{CONCLUSION}

In comparison with other natural textile fibers in use worldwide, silk occupies only a very small slice of world production, consumption and demand. In pure volume terms, the share of silk in the global fiber market is thus dwarfed by the two other major categories, namely, cotton and wool. Though the volume of silk trade is comparatively low, the value of international trade in silk and silk products is significant. The world demand for silk is on the increase particularly since the past two decades. Most of the small and cottage industry in our country is built up on the basis of the supply of agro-products. This agro-based silk industry leads a significant role in national economy and national development. Further, the industry has a strong equity orientation as large number of landless labours, marginal and small farmers depend on silk industry.

\section{REFERENCES}

[1] Vigneshwaravarmudy, "Silk Industry: Need To Become Competitive", Facts For You, December 2011, pp. 18-19.

[2] Geetha, G. S. Srinivasa, G. Jayaram, M. N. S. Iyengar and N. B. VijayaPrakash, "Socio-Economic Determinants of Farmer Oriented Technology Packages for Sericulture: A Field Study", Indian Journal of Sericulture, Vol. 40, No.1, pp. 96-99, 2001.

[3] R. Anitha, "Indian Silk Industry in the Global Scenario", EXCEL International Journal of Multidisciplinary Management Studies, Vol. 1, No. 3, pp. 100-110, December 2011.

[4] [Online].Available:www.tnsericulture.gov.in. 